\title{
ESPAÇOS PARA A OCIOSIDADE NA BIBLIOTECA
}

\section{ESPACIOS PARA EL OCIO EN LA BIBLIOTECA}

\author{
Sueli Bortolin - bortolin@uel.br \\ Doutora em Ciência da Informação pela Universidade \\ Estadual Paulista "Júlio de Mesquita Filho" (Unesp, Marília). \\ Professora do Departamento de Ciência da Informação da \\ Universidade Estadual de Londrina (UEL). \\ Márcia Crispim Junior - marcia.cj@hotmail.com \\ Bacharel em Biblioteconomia pela Universidade Estadual de \\ Londrina (UEL). \\ Rovilson José da Silva - rovilsonedu@hotmail.com \\ Doutor em Educação pela Universidade Estadual Paulista \\ "Júlio de Mesquita Filho" (Unesp, Marília). Professor do \\ Departamento de Educação da Universidade Estadual de \\ Londrina (UEL).
}

\begin{abstract}
RESUMO
Introdução: As bibliotecas sempre se apresentaram como possibilidades de busca de informação e cultura, mas ainda não são concebidas como local de ociosidade. Esse trabalho trata da ocioteca, isto é, espaço que leva os usuários a relaxar, descansar por meio da leitura.

Objetivo: Enfatizar a importância do ócio para os indivíduos, tendo as bibliotecas como espaços dessa prática.

Metodologia: A metodologia escolhida é a bibliográfica e tem como ponto de partida alguns textos em língua espanhola, publicados na Revista Educación y Biblioteca.

Resultados: Por se tratar de uma temática pouco discutida no dia a dia, os resultados são preliminares e inconclusos, por isso é um diálogo com os mediadores de leitura, para que estes influenciem as mudanças nas bibliotecas, podendo transformar-se em lugares destinados ao ócio e ao lazer.

Conclusão: A primeira conclusão é a possibilidade de viabilizar esses espaços, mas não basta apenas boa vontade, pois exige planejamento, elaboração de projetos de captação de recursos, formação de mediadores em prol de ambientes desse gênero.
\end{abstract}

Palavras-chave: Ocioteca. Biblioteca. Espaços de leitura. 


\section{INTRODUÇÃO}

A inspiração para o estudo dessa temática foi a Revista Educación y Biblioteca, uma publicação espanhola (2001) que em seu número 123 aborda as ociotecas e a ociosidade no universo das bibliotecas. Nosso interesse em pesquisar essa temática se justifica pela constatação de que a correria diária de trabalho, estudo, casa, filhos entre outros, faz com que as pessoas não deixem espaços para que ócio seja vivido da forma que melhor lhes aprouver.

A presença dos computadores é inegável e deve ser percebida também como fonte de informação e diversão. A sociedade do século $X X I$ vive uma avalanche de possibilidades para usufruir o ócio, pois com a evolução tecnológica mediada pelo fazer online, supostamente existiriam maiores condições para que as pessoas usufruíssem tempo para si, para atividades que possam ser consideradas seu ócio, mas isso não tem acontecido, o tempo parece cada vez mais escasso, principalmente, para o ócio pessoal.

No âmbito das atividades relacionadas ao ócio estão as bibliotecas, ou espaços que têm sido criados com o intuito de englobar informação, lazer, cultura, num mesmo ambiente, de modo a proporcionar tranquilidade com uma variedade de suportes informacionais, desde o tradicional impresso até a inovação digital.

Se a tecnologia tem facilitado muitas funções do dia a dia da sociedade, nas tomadas de decisão, no apoio à rotina das pessoas que resolvem parte de suas vidas por meio da tela do celular "nas pontas dos dedos". Todavia, por mais que os problemas sejam resolvidos com rapidez, as pessoas, muitas vezes, não conseguem se libertar do trabalho e outros compromissos, tornando-se dependentes dos mesmos. Vale destacar que não estamos atribuindo apenas à tecnologia a responsabilidade da evidente dependência dos sujeitos pelas máquinas na contemporaneidade, pois é ao indivíduo que cabe o planejamento do uso da mesma.

Com isso, a tranquilidade, possivelmente não se concretizará, já que todos parecem estar escravizados pela tecnologia, que embora 
facilite a vida das pessoas, são privadas de atividades relaxantes, como por exemplo, caminhar, jogar. Porém, isso não se deve somente à tecnologia, há também a cobrança que muitos impõem a si mesmos em outros contextos de trabalho sem a tecnologia.

O objetivo dessa pesquisa foi o de enfatizar a importância do ócio para os indivíduos, tendo as bibliotecas como espaços dessa prática. Como objetivos específicos: apontar os benefícios: que ócio e os espaços de ociosidade podem trazer aos indivíduos; apontar a importância da leitura para o leitor; propor arranjos espaciais possíveis para uma ocioteca.

Acreditamos que enfatizar o ócio na sociedade atual é fundamental, pois os indivíduos têm apresentado, na maioria das vezes, altos níveis de estresse, sendo uma obrigação dos equipamentos públicos proporem lugares de repouso ou atividades que transportem os indivíduos para o descanso tanto físico quanto psicológico.

Para tanto, este trabalho se divide em: Introdução, Ócio e a Ocioteca (concepções relacionadas ao ócio e a ocioteca), Mediação da Leitura e os espaços para a ociosidade (leitura, como distração, refúgio e ampliação do intelecto também nos momentos de ociosidade). Incluímos também os Procedimentos Metodológicos e as Considerações Finais.

Esperamos instigar acadêmicos e profissionais de área diversas, à reflexão e à proposição de novas pesquisas e publicações a respeito dessa temática que suscita maior desenvolvimento.

\section{2 ÓCIO E OCIOTECA}

Nessa pesquisa as palavras ócio e ociosidade foram apresentadas tendo como base inicial a Revista Educación y Biblioteca que no seu editorial explicita:

Para llevar a cabo las misiones que la biblioteca pública tiene asignadas, y que se articulan en torno a la información, la educación y la cultura, las colecciones deben incluir todos los tipos de materiales que reflejan 
las tendencias actuales y la evolución de la sociedad, así como la memoria del esfuerzo y la imaginación del ser humano. No son los soportes, en sí mismos, lo que nos interesa, sino la transmisión del patrimonio cultural que éstos contienen. (OCIOTECA, 2001).

A biblioteca é um dos espaços socioculturais que tem em sua essência o ócio. Embora seja utilizada para pesquisas científicas, acadêmicas, também contribui para pesquisas pessoais, sem nenhuma norma, que atendam apenas à curiosidade daquele que a procura: muitas pessoas se perdem por horas no espaço, nos livros, em aparatos tecnológicos que levam à leitura. Perder tempo, nesse caso, é ganhar espaço para si mesmo, deixar-se levar pelo ritmo que o espaço tem, ou que o leitor adquire no ambiente.

A leitura também é uma atividade ligada, muitas vezes, apenas ao ócio, pois para ler é preciso abandonar-se ao texto, transpor-se para outro espaço, tempo e assunto. É um percurso de ir e vir da pessoa para a leitura, da leitura para o mundo da pessoa e assim por diante, por conseguinte, demanda-se tempo para construir, amadurecer, apropriarse do que se leu. Nesse contexto está a biblioteca.

Vasconcelos, Villarouco e Soares $(2009$, p. 8 ) evidenciam que: "A função social da biblioteca, enquanto instituição social está principalmente em ser a interface, ou a mediadora entre indivíduos e o conhecimento de que eles necessitam."

Assim, o espaço de ociosidade na biblioteca tem como objetivo a interação entre pessoas e os diferentes textos em diversas linguagens. Este espaço pode ser também denominado ocioteca que para Crispim Junior (2014, p. 21) "[...] é um ambiente específico para a ociosidade com uma atmosfera lúdica e prazerosa onde os frequentadores poderão se apropriar da cultura, interagir, se divertir."

Ao focar a ocioteca explicitamos que entre seus objetivos está o de proporcionar liberdade para que seus usuários gostem de permanecer nele por um bom tempo. Independente dos diversos suportes que a biblioteca oferece aos seus usuários, o que realmente 
importa são os conteúdos que estes possuem para satisfazer as necessidades de seus frequentadores.

\section{MEDIAÇÃO DA LEITURA E OS ESPAÇOS PARA A OCIOSIDADE}

Com a infinidade de obrigações em nosso dia a dia, fica a desejar os cuidados com o nosso cérebro, dele é exigido um trabalho constante, sem descanso, assim, exaurido devido à rotina incessante do cotidiano, o indivíduo, em geral, transforma a existência num ato quase mecânico, praticamente utilitarista, sem levar em conta a sua subjetividade, sem espaço para "[...] uma ruptura da monotonia em vários campos da realidade: arte, politica, subjetividade, comportamento, gosto, moral." (FERRAZ, 2005, p. 5).

Assim exercitar o cérebro não significa estar com ele o tempo todo ativo em assuntos de trabalho e soluções para questão preocupantes, mas sim disponível para as atividades criativas que estimulem a sensibilidade, a observação, à audição, aos jogos, à leitura (seja ela escrita, sonora, imagética etc.).

A prática da leitura, por exemplo, pode acontecer espontaneamente ou pelo compartilhamento e incentivo de terceiros (indicar, recomendar histórias, estilos e outros). Este é o papel de mediador que pode motivar as pessoas direta ou indiretamente à leitura.

Da mesma forma, salientamos que a motivação para uma ociosidade é necessária, visto que a maioria das pessoas (talvez pela influência religiosa, sendo a preguiça é um dos pecados capitais) acredita que a ociosidade é mau uso do tempo.

Quando estamos em grupo o comportamento muda, a relação com outras pessoas nos deixa menos gregários, portanto, necessitamos de pessoas ao nosso redor para nos incentivar à leitura, para jogar xadrez, caminhar; sendo isso essencial, para o relaxamento e a diminuição do estresse. 
As bibliotecas são equipamentos culturais que desempenham um papel fundamental na sociedade, defendemos que elas sejam concebidas também como um local de ócio, contudo devido à precariedade das instalações de nossas bibliotecas, sua falta de estrutura, aparência de improviso e acomodações impróprias podem cansar ou causar desconforto, enfim ficam longe de ser um convite à frequência e a convivência, o que contribui para que os usuários optem por não frequentá-las.

Si con estos servicios la biblioteca ya está ofreciendo un ocio cultural, ¿por qué, entonces, la biblioteca restringe el uso de las tecnologías de la información e Internet a búsquedas bibliográficas o cuestiones de información práctica negándose a sí misma como recurso de ocio? (OCIOTECA, 2001).

No Brasil, na atualidade, encontramos poucos edifícios que são construídos especificamente com a finalidade de instalar uma biblioteca, são exceções a Biblioteca de São Paulo (Parque da Juventude), Biblioteca Parque Estadual (Rio de Janeiro - centro). As instituições, principalmente localizadas nos grandes centros, tornam-se espaço de apropriação da informação da leitura, de interação e ociosidade.

Quais são os espaços onde lemos constantemente? Será que estes lugares são confortáveis? Tudo é uma questão de tempo até que determinada posição ou barulho incomodem. Pensando na questão do conforto há livrarias que investem em mobiliários confortáveis para os seus clientes, mas é evidente que visam ao retorno comercial imediato que este conforto irá prover. Esse não é o caso da biblioteca, ela deve também seduzir, mas o retorno é social e cultural, algo subjetivo e não mensurável.

Gómez Hernández e García Gómez (2001, p. 62) defendem que: "Una biblioteca, sin renunciar al fomento de los modos tradicionales de lectura, pero reconociendo la multiplicidad de códigos y formas de leer, debe abrirse a las nuevas formas de ocio existentes [...]". Portanto, os mediadores devem estar atentos aos recursos tecnológicos que têm seduzido os usuários, visto que estes podem ampliar o acesso aos 
diversificados textos digitais de maneira presencial, bem como utilizando os dispositivos móveis.

Assim podemos explorar diferentes modos de leitura, com o intuito de mostrar que há outros materiais que oferecem conteúdos motivadores para o usuário aproveitar seu tempo livre. $\mathrm{O}$ acesso à internet possibilita aos usuários a pesquisa, estudos, lazer, novas descobertas, curiosidade, entre muitas outras atividades.

A Biblioteca Parque Estadual, no centro do Rio de Janeiro, talvez seja um dos prédios mais modernos em instalações e concepção de espaço público para leitura, informação e ócio no Brasil. Embora no ambiente existam vários espaços que dão ao usuário a possibilidade de estar em conjunto, isolar-se, meditar, ou quem sabe tirar uma soneca, há o Lugar do Ócio nominado especialmente para isso, conforme é possível constatar na figura a seguir:

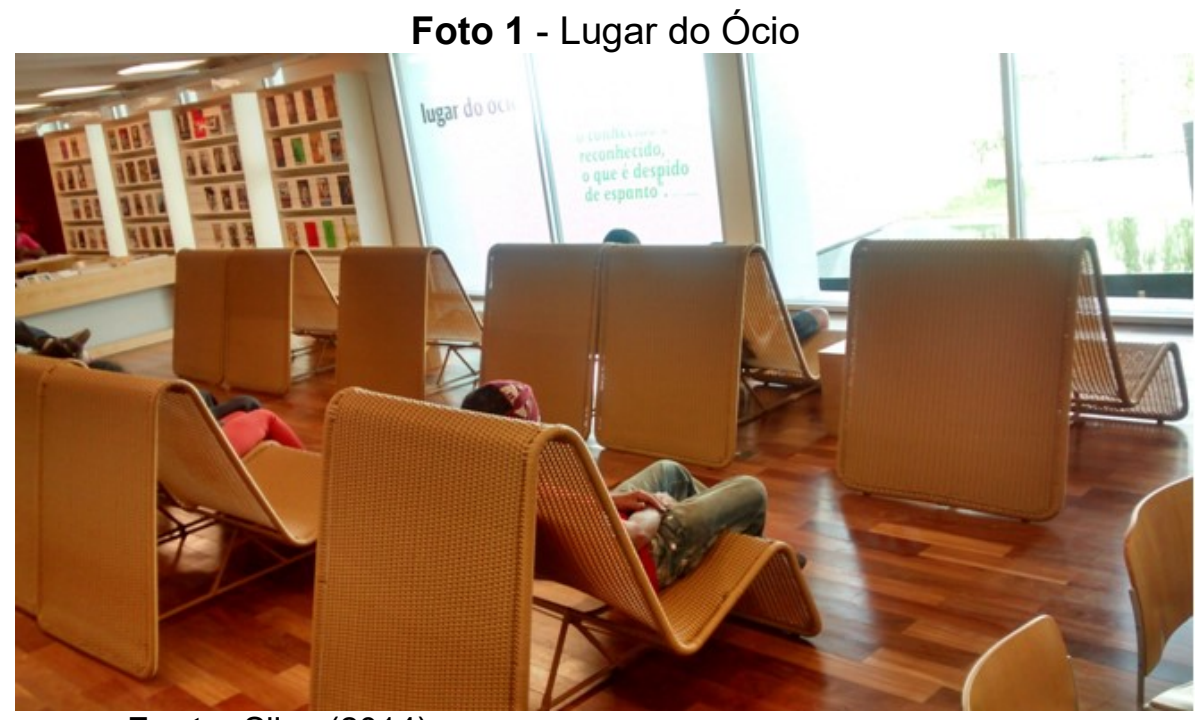

Fonte: Silva (2014)

Essas cadeiras são confortáveis e auxiliam o corpo a largar-se, acomodar-se frente à parede com janelas inteiriças de vidro de onde se pode visualizar a área aberta interna, com jardim, escultura, espelho d'água, bancos e cadeiras para os usuários.

É também inovador e recomendável na biblioteca o uso de redes para que os frequentadores possam realizar suas leituras, deitados, ou simplesmente usufruir da rede para pensar, observar, desenhar, conversar descontraidamente. 
Sueli Bortolin; Márcia Crispim Junior; Rovilson José da Silva Espaços para a ociosidade na biblioteca

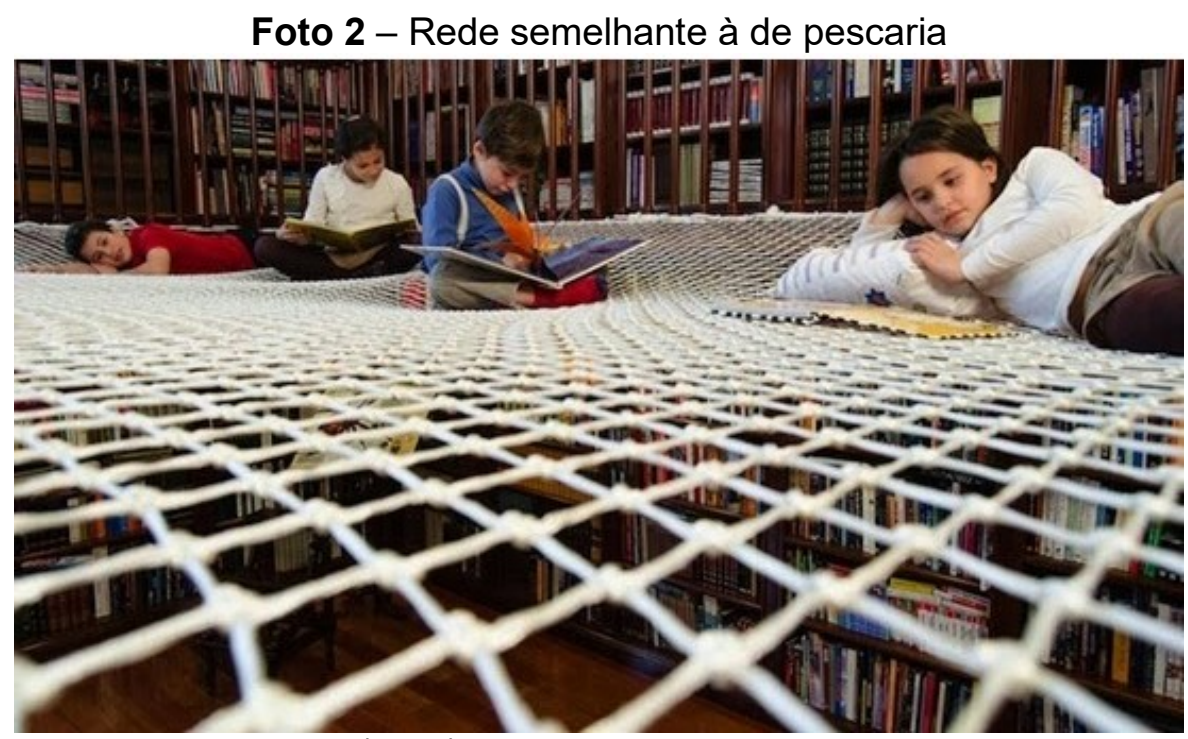

Fonte: Jensen (2013)

Lamentavelmente, em sua maioria, as bibliotecas brasileiras são lugares que não trazem aprazibilidade, pois quase sempre apresentam ambientes e mobília que não convidam o usuário a permanecer ali. Uma modelo a ser copiado está na Biblioteca Parque Estadual - RJ (foto 3):

Foto 3 - Biblioteca Parque Estadual - RJ

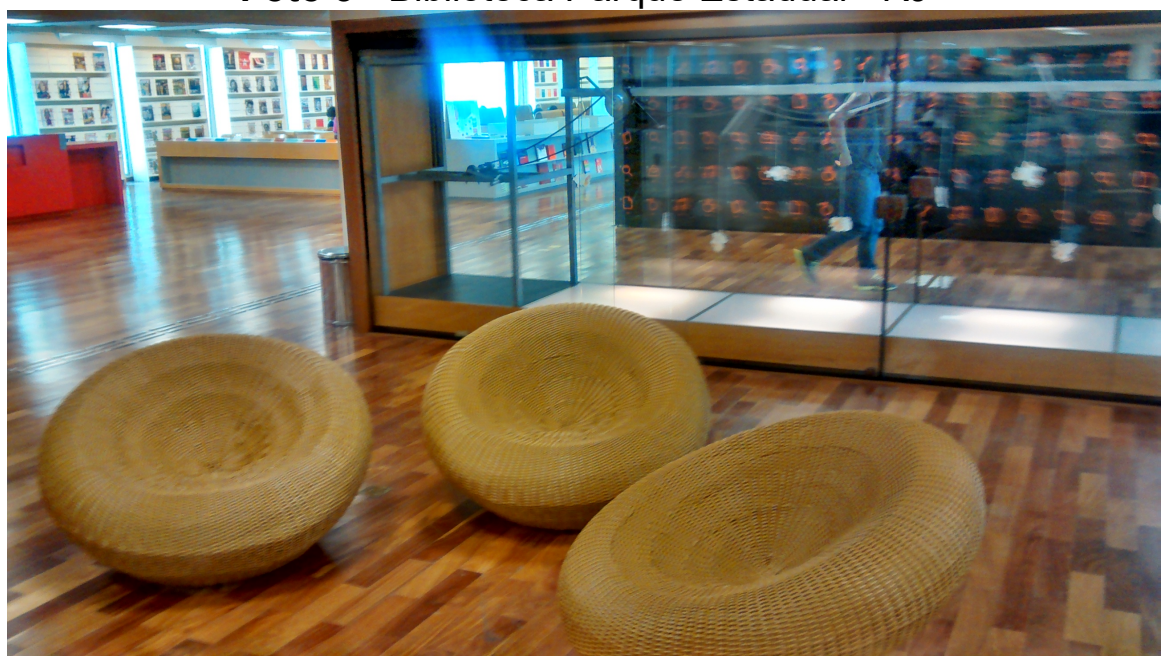

Fonte: Silva (2014)

A aparente informalidade aliada ao conforto convida à utilização do espaço. Ainda na perspectiva de oferecer conforto e permanência, a instalação de bicicletário pode ser um atrativo e incentivo econômico para os frequentadores da ocioteca, visto que, faz com que eles não gastem dinheiro e sintam segurança em deixar seu meio de transporte do lado de fora sem a preocupação com roubos. 
Foto 4 - Bicicletário da Biblioteca Parque Estadual - RJ

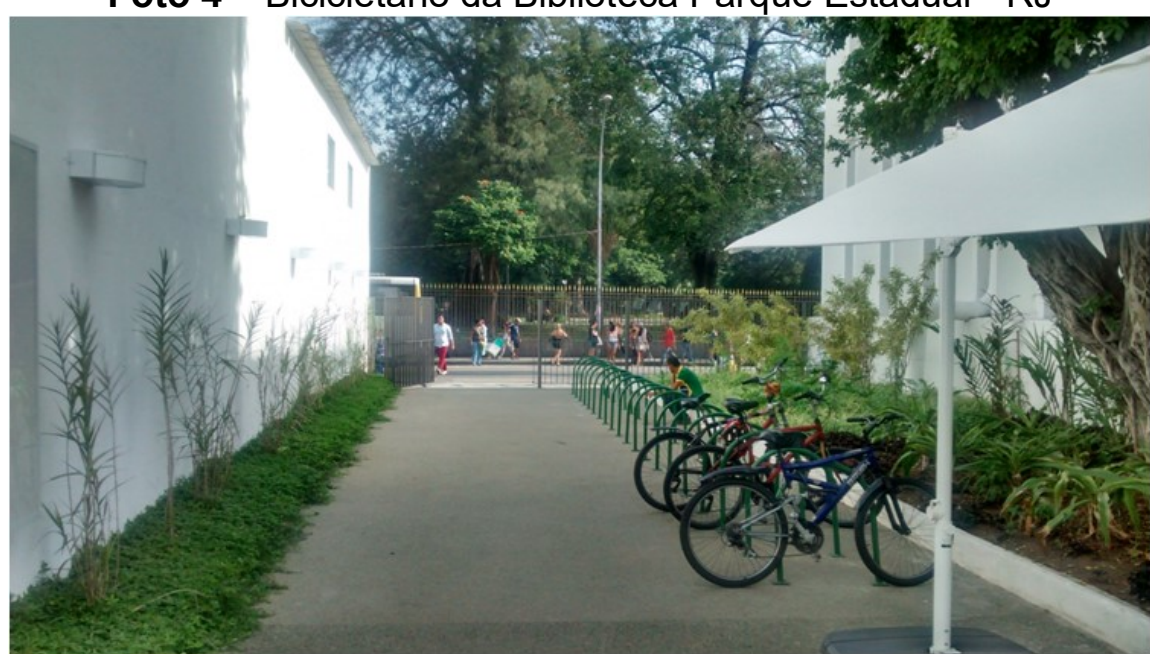

Fonte: Silva (2014)

Nesse contexto, as cores utilizadas nos ambientes da biblioteca ou ocioteca colaboram para o bem-estar do usuário, por isso vale analisar a proposta de Azevedo, Santos e Oliveira (2013, p. 7), que, baseados em diferentes estudiosos, apresentam no quadro a seguir a classificação e os significados atribuídos as cores (primárias e secundárias). 
Quadro 1 - As cores e seus significados

\begin{tabular}{l} 
AMARELO: cor quente, estimulante, de vivacidade e luminosidade. Tem elevado \\
índice de reflexão, e sugere proximidade. Se usado em excesso, pode-se tornar \\
monótono e cansativo. Boa para ambientes onde se exija concentração, pois atua \\
no SNC (Sistema Nervoso Central). É utilizada terapeuticamente para evitar \\
depressão e estado de angústia. \\
AZUL: está associadona cultura ocidental, a fé, confiança, integridade, delicadeza, \\
pureza e paz. O azul escuro dá a sensação de frieza e formalismo. \\
LARANJA: cor estimulante e de vitalidade. Está relacionada com ação, entusiasmo \\
e força. Possui grande visibilidade, chamando a atenção para pontos que devem \\
ser destacados. \\
\hline ROSA: aquece, acalma e relaxa. Está ligada à fragilidade, feminilidade e \\
delicadeza. \\
VERDE: quando em tom claro transmite sensação de paz e bem estar. E uma cor \\
que sugere tranqüilidade (sic), dando a impressão de frescor. Tons escuros desta \\
cor tendem a deprimir. \\
VERMELHO: cor estimulando. Desperta entusiasmo, dinamismo, ação e violência. \\
Dá sensação de calor e força, estimulando os instintos naturais e sugerindo \\
proximidade. Se usada em excesso pode irritar, desenvolver sentimentos de \\
intranquilidade e despertar violência. \\
VIOLETA: em excesso torna o ambiente desestimulante e agressivo, leva à \\
melancolia e depressão. Sugere muita proximidade, contato com os sentimentos \\
mais elevados e com a espiritualidade. Assim como o vermelho, o azul escuro e o \\
verde escuro, não são recomenda o uso em grandes áreas.
\end{tabular}

Fonte: Azevedo, Santos e Oliveira (2013)

Equilibrar o uso das cores, em conjunto com os profissionais de Arquitetura, também é uma iniciativa do mediador de leitura. A preocupação com a estabilidade das cores é essencial, principalmente porque o acervo, por si, com as capas dos documentos coloridos, podem sobrecarregar o ambiente.

A iluminação também é um detalhe fundamental, pois a luz nos ajuda a enxergar onde estamos andando, o que estamos ingerindo, o que estamos lendo, melhor dizendo, o que nos cerca. Pérez Ferrés (2008, p. 46) afirma que: "Os quatro elementos que interferem diretamente na percepção de objetos são o tamanho destes, a luminosidade, o contraste de luminosidade entre o objeto e o entorno, e o tempo de exposição do objeto ao campo visual do olho." Este cuidado 
propicia o conforto visual para a leitura, em especial, para aqueles que necessitam de maior luminosidade para acuidade visual.

Pensando na necessidade de luz, a construção da ocioteca terá como uma de suas prioridades a captação de luz natural com a instalação de grandes vidraças, fazendo com que haja iluminação na maior parte do dia, sendo esta uma contribuição econômica e ecológica para a sociedade. Entretanto, quando o sol se puser, haverá necessidade de recorrer à luz artificial.

Nossa sugestão é que exista a iluminação geral do ambiente, apoiada pelas luminárias individuais, pois elas poderão dar suporte aos usuários com baixa visão no uso dos materiais disponíveis, ajudando-os na locomoção dentro do recinto, para que não seja surpreendido com elementos que poderão provocar algum acidente.

Quanto ao mobiliário para leitura, podem-se utilizar poltronas que serão distribuídas em diferentes ambiente para leitura ou as pessoas ficarem ali sentadas, pensar à vontade, observar, fazer uso de aplicativos no seu celular.

Foto 4 - Estantes da Biblioteca Parque Estadual - RJ

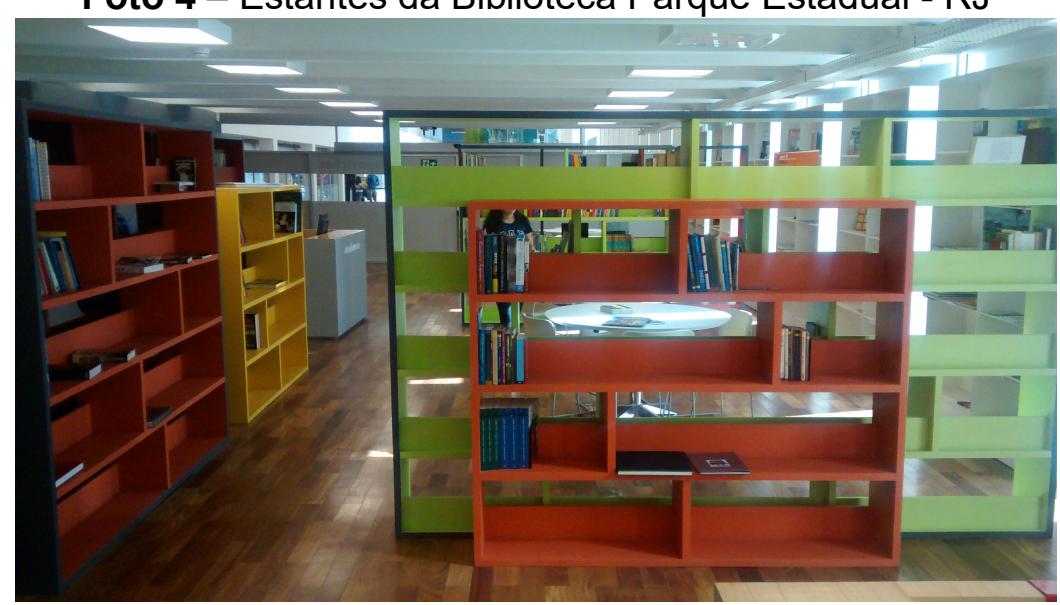

Fonte: Silva (2014)

Contudo, ao pensarmos nesta proposta de mobiliários lúdicos e diferentes do que estamos acostumados a ver, também nos preocupamos com o outro aspecto importante, isto é, o tamanho das estantes. Sugerimos que as estantes tenham a altura de uma estatura média para facilitar o acesso de todos aos livros. Além disso, não podem ser muito altas, para permitir ao cadeirante autonomia e integração ao 
espaço, assim evitando constrangimentos. No caso das crianças, as estantes sendo baixas elas poderão pegar livros, brinquedos, sem ficar dependente da intervenção do adulto.

A ocioteca ou a biblioteca com espaço específico para a ociosidade é um lugar de liberdade, descontração e leveza, mas alguns deveres e direitos devem nortear o comportamento dos usuários, a fim de convivência tranquila, sem tensões. Aqui se propõe a apresentação (impressa ou em mural) de alguns itens a serem respeitados, visto que eles serão fundamentais para o andamento da biblioteca. Por exemplo, deixar suas bolsas, mochilas dentro dos armários oferecidos gratuitamente pela biblioteca. Preferencialmente cada usuário trará seu cadeado, visando maior segurança de seus pertences. Nesse espaço é recomendável armários no tamanho da figura 6 , pois além de material escolar, roupas, algumas pessoas podem estar com seus patins, patinetes, skate entre outros.

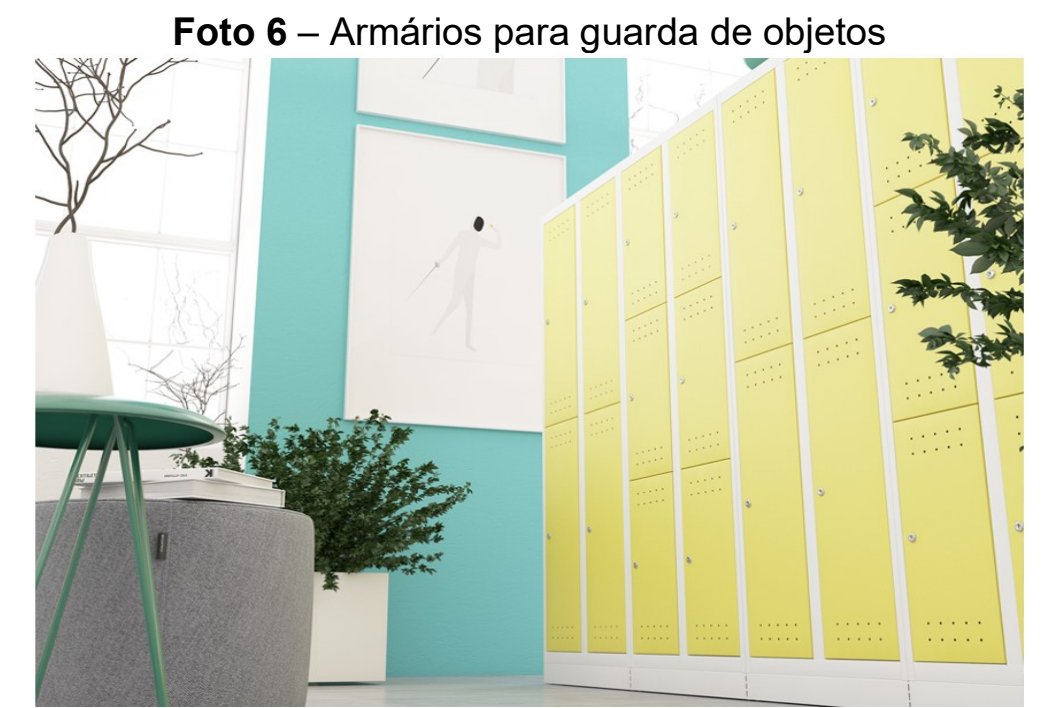

Fonte: Biccateca (2014)

Reforçamos a nossa defesa de que o ócio propicia saúde ao corpo e à mente, contribuindo com a criação, inovação e o bem-estar humano, por isso a necessidade de se criar no ambiente da biblioteca possibilidades para que o usuário reconstrua ou ressignifique o seu uso, o estar ali; viva o ócio para reconstruir-se, refletir sobre o que leu, estar perto de todos e, ao mesmo tempo, em um lugar particular seu no ambiente público. 


\section{PROCEDIMENTOS METODOLÓGICOS}

A decisão de pesquisar a ocioteca, talvez tenha sido um ato mais de curiosidade do que de espírito investigativo. Será que em termos de Ciência, isto é ruim? Justifica-se essa iniciativa tendo como base a defesa de Almeida Júnior (2005, p. 162) de que "[...] o autor não consegue ser isento ou imparcial. A própria escolha do tema a ser pesquisado já o identifica com os interesses do pesquisador e vem previamente carregado, por parte deste, de simpatia ou de antipatia." Neste caso, a opção foi de simpatia, mas também pela a inexistência em terras brasileiras de pesquisas nesta temática.

Para isso, escolhemos como metodologia a pesquisa bibliográfica que para Witter (1990, p. 25) "[...] pode ter por suporte da informação a produção científica de um dado autor. Neste caso, além da obra do ou dos autores estudados, ao levantar a bibliografia, o pesquisador deverá buscar trabalhos anteriores focalizando a referida produção."

Este gênero de pesquisa deve, segundo Marconi e Lakatos (2011), seguir três etapas, sendo elas: identificação (fase do reconhecimento do assunto), localização (obtenção das informações necessárias) os documentos e compilação (reunião sistemática das referências e informações).

Assim, em posse das poucas publicações encontradas a respeito de ocioteca, construímos algumas relações com temáticas como: ergonomia, uso da cor, tecnologias, mobiliário, iluminação entre outros.

Crispim Junior (2014, p.43) destaca que esse espaço deve "[...] oferecer produtos/serviços, mobilizando os usuários a relaxar, descansar por meio da leitura de literatura."

\section{CONSIDERAÇÕES FINAIS}

Desde o surgimento da civilização que a biblioteca tem se adequado às necessidades de cada época e, atualmente, também está em transformação, reorganizando estruturas e alterando as suas mediações. Mediações essas que, cada vez mais, tendem a ocorrer por 
meio de mídias e dispositivos. O ambiente da biblioteca é dinâmico e exigirá continuamente busca de soluções inovadoras, como é o caso dos espaços que remetem ao ócio.

Para a sociedade em ebulição, com um cotidiano na velocidade da instantânea da internet, entrar numa biblioteca e preparar-se para enfrentar o mundo em outra dimensão, como é a leitura, mais lenta e, ao mesmo tempo, mais profunda, que instiga a reflexão $e$ autocompreensão torna-se necessário.

Para finalizar, consideramos que é possível viabilizar esses espaços e, para tanto, os mediadores devem recorrer à projetos de captação de recursos, em especial, quando se trata de instituições públicas, onde eles, os recursos, geralmente, são parcos para as bibliotecas.

\section{REFERÊNCIAS}

ALMEIDA JÚNIOR, Oswaldo Francisco de. Sobe os métodos e as técnicas de pesquisa: reflexões. In: VALENTIM, Marta Lígia Pomim (Org.). Métodos qualitativos de pesquisa em Ciência da Informação. São Paulo: Polis, 2005. p. 161-171.

AZEVEDO, Maria de Fátima Mendes de; SANTOS, Michelle Steiner dos; OLIVEIRA, Rúbia de. 0 uso da cor no ambiente de trabalho: uma ergonomia da percepção. Guia do aluno. 2013. Disponível em: $<$ http://www.gastronomiabh.com.br/arquivos/AV1-cores.pdf>. Acesso em: 02 set. 2014. (Não paginado).

BICCATECA. Disponível em:

$<$ http://biccateca.com.br/biccatecasite/linha-multi/>. Acesso em: 06 out. 2014.

CRISPIM JUNIOR, Márcia. Ocioteca: uma proposta para mediação da literatura. 2014. 49f. Trabalho de Conclusão de Curso (Graduação em Biblioteconomia) - Universidade Estadual de Londrina. Londrina, 2014.

FERRAZ, Eucanaã. Veneno antimonotonia: os melhores poemas e canções contra o tédio. Rio de Janeiro: Objetiva, 2005. 
GÓMEZ HERNÁNDEZ, José Antonio; GARCÍA GÓMEZ, Juan Carlos. La biblioteca pública y la oferta de servicios de ócio basados em recursos eletrônicos. Educación y biblioteca, v.13, n. 123, p. 62-67, 2001. Disponível em:

<http://gredos.usal.es/jspui/bitstream/10366/118770/1/EB13_N123_P6267.pdf>. Acesso em: 19 maio 2014.

JENSEN, Claus. Conectados com a leitura pela rede. Blumenews. 2013. Disponível:

$<$ http://www.blumenews.com.br/site/index.php/colunas/colunas/item/898 0-conectados-com-a-leitura-pela-rede>. Acesso em: 04 out. 2014.

MARCONI, Marina de Andrade; LAKATOS, Eva Maria. Técnicas de pesquisa. 7. ed. São Paulo: Atlas, 2011.

OCIOTECAS. v. 13, n. 123, maio/jun. 2001. Educación y biblioteca, Disponível em: <http://es.youscribe.com/catalogue/libros/conocimientos/ ciencias-humanas-y-sociales/educacion-y-biblioteca-n-123-numerocompleto-1785375>. Acesso em: 29 maio 2014. (Não paginado).

PÉREZ FERRÉS, Sofia. Acessibilidade física. In: PUPO, Deise Tallarico; MELO, Amanda Meincke; PÉREZ FERRÉS, Sofia. (Org.).

Acessibilidade: discurso e prática no cotidiano das bibliotecas. Campinas: Unicamp, 2008.

SILVA, Rovilson José da. Acervo Pessoal: fotos 1, 3, 4, 5 e 6. Rio de Janeiro: Biblioteca Parque Estadual - RJ, 2014.

VASCONCELOS, Christianne Soares Falcão; VILLAROUCO, Vilma; SOARES, Marcelo Márcio. Avaliação ergonômica do ambiente construído: estudo de caso em uma biblioteca universitária. Revista Brasileira de Ergonômia, v. 4, n. 1, p.5-25, 2009. Disponível em: <http://www.abergo.org.br/revista/index.php/ae/article/view/69/66>. Acesso em: 20 ago. 2014.

WITTER, Geraldina Porto. Pesquisa bibliográfica, pesquisa documental e busca da informação. Estudos de Psicologia, v.7, n.1, p.5-30, jan./jul. 1990.

\section{Title}

Leisure spaces in libraries

\section{Abstract}

Introduction: Libraries are usually presented as spaces for active information and culture search, and are not often conceived as places for leisure. This paper adresses the concept of "ocioteca" that is; libraries where patrons go for relaxing and unwind by reading. 
Objective: This research emphasizes the importance of leisure for individuals, considering libraries as spaces for such practice.

Methodology: The study followed the bibliographical research method to examine papers published in the Spanish journal named Educación y Biblioteca. Because this is a fairly new and little discussed subject.

Results: Results allowed only preliminary conclusions, which can be seen by reading mediators as an opportunity for promoting changes in libraries, and turn them into spaces for leisure and recreation.

Conclusion: Research findings highlight the importance of considering planning, fundraising projects, and training as key steps for enabling such library spaces.

Keywords: "Ocioteca”. Libraries. Reading area.

\section{Titulo}

Espacios para el ocio en la biblioteca

\section{Resumen}

Introducción: Las bibliotecas siempre se presentaran como posibilidades de búsqueda, de información y de cultura, pero no están diseñados como un lugar de ocio. Este artículo trata de la ocioteca, es decir, el espacio que lleva a los usuarios para descansar, relajarse leyendo.

Objetivo: El objetivo es enfatizar la importancia del ocio para las personas y las bibliotecas como espacios de esta práctica.

Metodología: La metodología elegida es la investigación bibliográfica y tiene como punto de partida algunos textos en español, publicados en la revista Educación y Biblioteca.

Resultados: Como se trata de un tema poco discutido sobre uma base diaria, los resultados son preliminares y no concluyentes, por lo que es un diálogo con los mediadores de lectura, de manera que influyen en los cambios en las bibliotecas, pueden ser transformados en lugares destinados al ocio.

Conclusión: La primera conclusión es la capacidad de hacer que estos espacios, pero no lo suficiente buena voluntad, se requiere planificación, preparación de proyectos de recaudación de fondos, capacitación de mediadores en favor de este tipo de ambientes.

Palabras clave: Ocioteca. Biblioteca. Espacios lectura.

Recebido em: 15/03/2015

Aceito em: 10/09/2015 